\title{
In situ formation of Ge nanoparticles by annealing of Al- Ge-N thin films followed by HAXPES and XRD
}

Kristina von Fieandt ${ }^{*}$, Fredrik O. L. Johansson ${ }^{\ddagger}$, Olivier Balmes ${ }^{\S}$, Rebecka Lindblad ${ }^{\dagger}$, Lars Riekehr ${ }^{\dagger}$, Andreas Lindblad ${ }^{\ddagger}$, Erik Lewin $^{*} \dagger$

† Inorganic chemistry research programme, Department of Chemistry - Ångström laboratory, Uppsala University, Box 538. SE-75121, Sweden

‡ Division of Molecular and Condensed Matter Physics, Department of Physics and Astronomy, Uppsala University, Box 516, SE-75120 Uppsala, Sweden

$\S$ MAX IV Laboratory, Lund University, PO box 118, SE-22100 Lund, Sweden

\section{SUPPORTING INFORMATION}

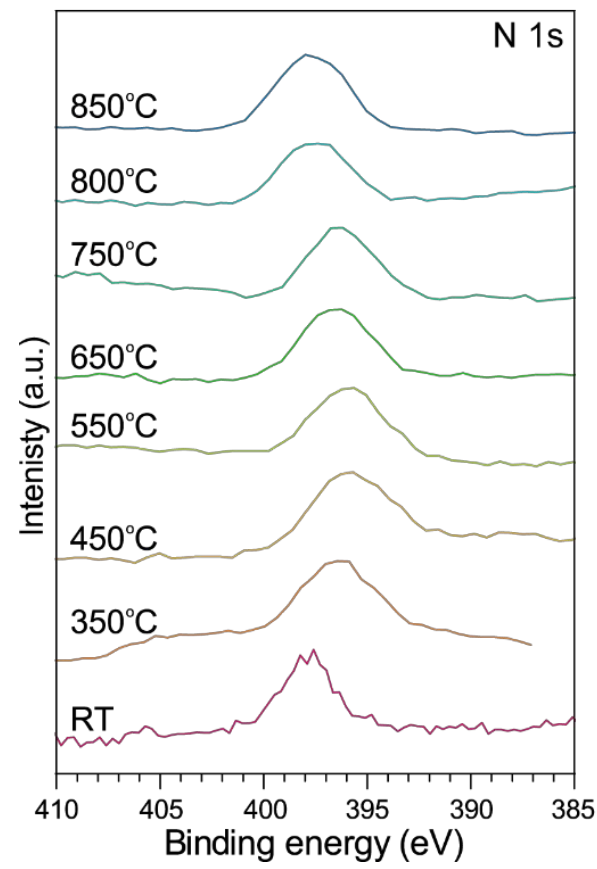

Figure S1. N 1s spectra obtained during the annealing experiment between room temperature (RT) and $850^{\circ} \mathrm{C}$.

The peaks shift to a lower binding energy for the $\mathrm{N} 1 \mathrm{~s}$ spectra obtained up to $750^{\circ} \mathrm{C}$ compared to the spectrum recorded at room temperature, which can be attributed to a decrease of oxygen on the surface as heat is applied. For the spectra attained at $800^{\circ} \mathrm{C}$ and $850^{\circ} \mathrm{C}$ the peaks are shifted to a higher binding energy, indicating a change in the chemical environment for nitrogen that can be correlated to the release of $\mathrm{N}_{2}$ in the films. 


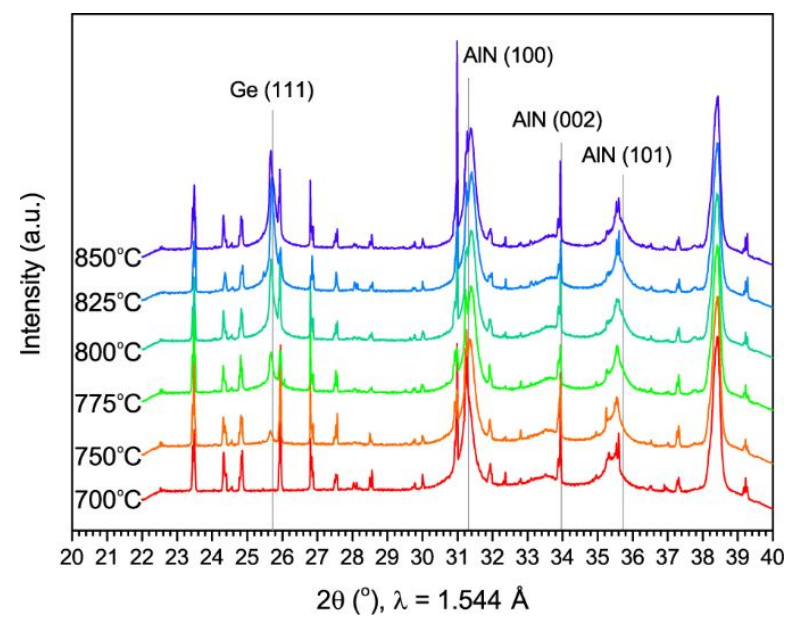

Figure S2. X-ray diffractograms recorded for the annealing experiment that ranged between $700^{\circ} \mathrm{C}$ and $850^{\circ} \mathrm{C}$ with the peaks from the sample holder included in the scans.
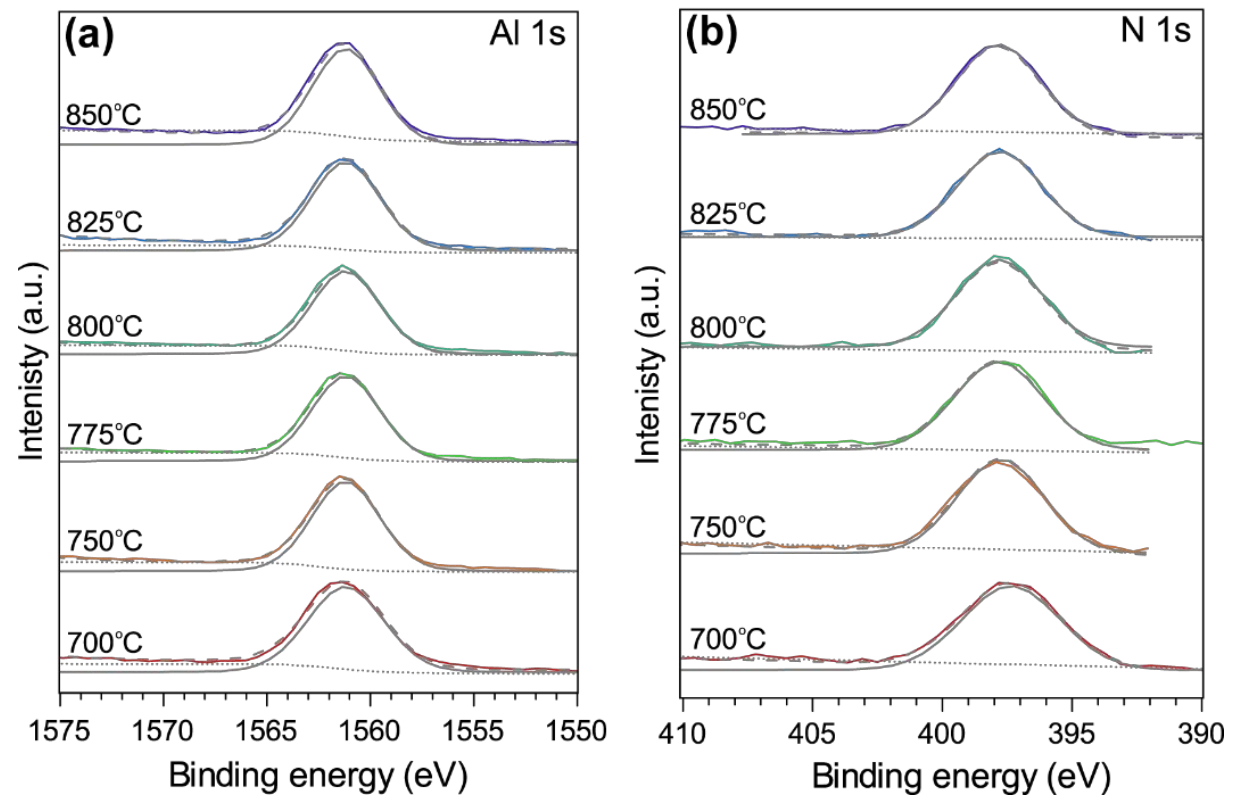

Figure S3. (a) Al 1s and (b) N 1s spectra for the annealing experiment between $700^{\circ} \mathrm{C}$ and $850^{\circ} \mathrm{C}$. Peak fittings of the Al 1s and N 1s core levels were performed using Voight profiles. For Al 1s a Shirley background and a Lorentzian width of $0.42 \mathrm{eV}^{1}$ was used. The N1s core levels were fitted with a linear background and a Lorentzian width of $0.12 \mathrm{eV} .^{2}$ The $\mathrm{Al} 1 \mathrm{~s}$ peaks do not undergo any significant changes upon annealing and is used for charge referencing. The $\mathrm{N}$ 1s peaks slightly shifts to higher binding energy between $700^{\circ} \mathrm{C}$ and $750^{\circ} \mathrm{C}$, which is connected to the release of $\mathrm{N}_{2}$ gas release in the films in accordance with the $\mathrm{N} 1 \mathrm{~s}$ spectra obtained for the annealing experiment between $\mathrm{RT}$ and $850^{\circ} \mathrm{C}$. 

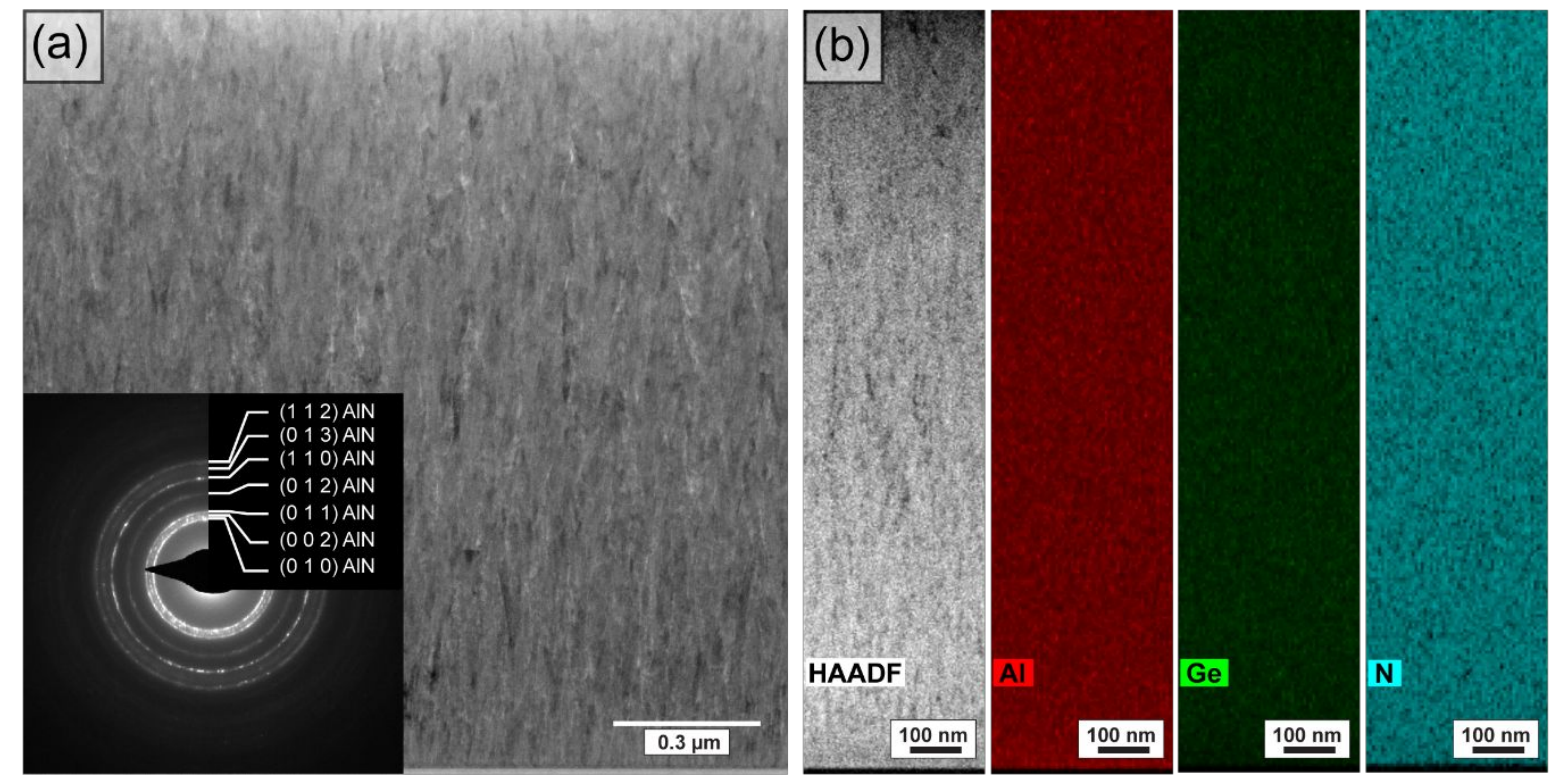

Figure S4. (a) Bright field STEM image of the cross section of the Al-Ge-N sample in the as-deposited state, showing a nanocrystalline and dense film. The electron diffraction pattern is shown as an inset and confirms the AlN wurzite-type structure of the film. (b) HAADF-STEM image of the cross section of the as deposited Al-Ge$\mathrm{N}$ film and corresponding EDX maps where a homogenous distribution of $\mathrm{Ge}, \mathrm{Al}$ and $\mathrm{N}$ is shown.

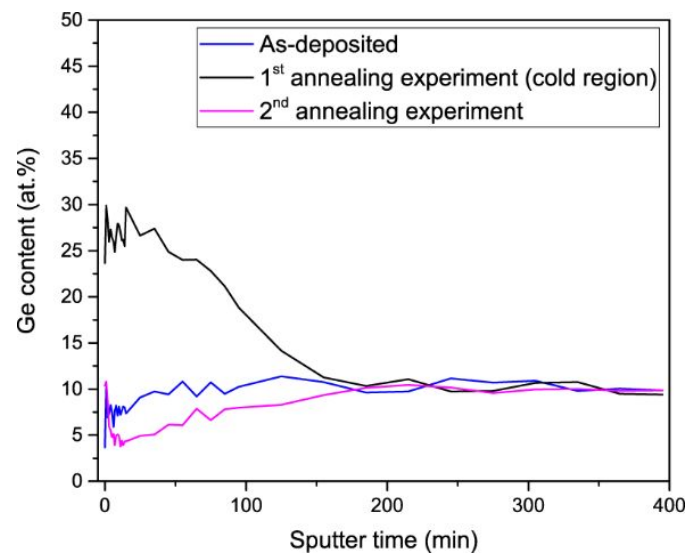

Figure S5. XPS sputtered depth profiles of the Ge content for the as-deposited film, for the sample from the first annealing experiment, which was non-homogenously heated, of the cold region (i.e. rich in Ge particles) and for the sample of the second annealing experiment, which was homogenously heated. The latter sample shows a concentration gradient and less Ge content for low sputter time, i.e. near the surface, compared to the asdeposited sample and the sample from the first annealing experiment, indicative of loss of Ge near the surface.

\section{References}

1. Krause, M. O.; Oliver, J. H., Natural widths of atomic K and L levels, K $\alpha$ X-ray lines and several KLL Auger lines. J. Phys. Chem. Ref. Data 1979, 8, 329-338.

2. $\quad$ Feifel, R.; Andersson, M.; Sörensen, S. L.; Piancastelli, M. N.; Tchaplyguine, M.; Björneholm, O.; Karlsson, L., A quantitative analysis of the $\mathrm{N} \mathrm{1s-pi*} \mathrm{photoabsorption}$ 
profile in $\mathrm{N}_{2}$ : new spectroscopical constants for the core-excited state. Chem. Phys. Lett. 2004, (383), 222-229. 